\title{
How often should sitting and rising from a chair be evaluated in patients with Duchenne muscular dystrophy?
}

\author{
Com que frequência deve ser avaliada a atividade de sentar e levantar da cadeira em \\ pacientes com distrofia muscular de Duchenne? \\ Michele Emy Hukuda', Fátima Aparecida Caromano', Renata Escorcio', Eduardo Vital de Carvalho', \\ Silvana Maria Blascovi-Assis², Mariana Callil Voos ${ }^{1}$
}

\begin{abstract}
Objective: To determine how often sitting/rising from a chair should be assessed in Duchenne muscular dystrophy (DMD) patients to avoid redundant/missing data. Methods: Sitting/rising from a chair was evaluated in 26 DMD children (5-12yrs), in three-month intervals, over twelve months, with the Functional Evaluation Scale (domain sitting/rising from a chair). Scores were compared by effect sizes (ES) and standardized response means (SRM) (responsiveness analysis). Results: Sit-to-stand showed low-to-moderate responsiveness in three-month intervals (ES:0.23-0.32; SRM:0.36-0.68), moderate-to-high responsiveness in six-month intervals (ES:0.52-0.65; SRM:0.76-1.28), high responsiveness at nine-month (ES:0.84-0.91; SRM:1.26-1.64) and twelve-month intervals (ES:1.27; SRM:1.48). Stand-to-sit showed low responsiveness in three-month intervals (ES:0.26-0.49; SRM:0.37-0.42), moderate responsiveness in six-month intervals (ES:0.50-0.78; SRM:0.56-0.71), high responsiveness in nine-month (ES:0.94-1.00; SRM:0.84-1.02) and twelve-month intervals (ES:1.13; SRM:1.52). Conclusion: Six months or longer intervals for reassessment are indicated to evaluate sitting/standing from a chair in DMD patients.
\end{abstract}

Keywords: muscular dystrophy, Duchenne; motor activity; task performance and analysis; outcome assessment (health care); physical examination.

\section{RESUMO}

Objetivo: Determinar a frequência de avaliação do sentar e levantar da cadeira em pacientes com distrofia muscular de Duchenne (DMD), para evitar informações faltantes ou redundantes. Métodos: Sentar/ Levantar foram avaliados em 26 crianças com DMD (5-12 anos), em intervalos de três meses, durante doze meses, com a Escala de Avaliação Funcional (domínio sentar/ levantar da cadeira). Os tamanhos do efeito (TE) e as médias de resposta padronizada (MRP) foram usados na análise de responsividade. Resultados: Levantar da cadeira teve responsividade baixa a moderada em três meses (TE: 0,23-0,32; MRP: 0,36-0,68), moderada a alta em seis meses (TE: 0,52-0,65; MRP: 0,76-1,28), alta em nove e (TE: 0,84-0,91; MRP: 1,26-1,64) doze meses (TE: 1,27; MRP: 1,48). Sentar na cadeira teve responsividade baixa em três meses (TE: 0,26-0,49; MRP: 0,37-0,42), moderada em seis meses (TE: 0,50-0,78; MRP: 0,56-0,71), alta em nove (TE: 0,94-1,00; MRP: 0,84-1,02) e doze meses (TE: 1,13; MRP: 1,52). Conclusão: Os pacientes com DMD devem ser reavaliados com intervalos mínimos de seis meses entre avaliações de sentar/ levantar da cadeira.

Palavras-chave: distrofia muscular de Duchenne; atividade motora; análise e desempenho de tarefas; avaliação de resultados (cuidados de saúde); exame físico.

In Duchenne muscular dystrophy (DMD), muscle weakness results in progressive functional independence $\operatorname{loss}^{1}$. Studies have shown the relevance of motor function follow up to monitor DMD accurately ${ }^{2,3,4}$. Global motor scales should be complemented by functional tasks assessment because, despite the continued decline in muscle strength, children with DMD continue to perform the activities using compensatory movements 5 . The analysis of compensatory movements employed during functional activities shows the changes in muscular synergies. Compensatory movements are performed by DMD patients to compensate for muscle weakness, mobility loss, and to deal with task demands ${ }^{6}$.

The Functional Evaluation Scale for Duchenne muscular dystrophy (FES-DMD) provides detailed information about

${ }^{1}$ Universidade de São Paulo, Faculdade de Medicina, Laboratório de Fisioterapia e Comportamento, São Paulo SP, Brasil;

¿Universidade Mackenzie, Faculdade de Fisioterapia, São Paulo SP, Brasil.

Correspondence: Mariana Callil Voos; Rua Cipotânea, 51; 05360-000 São Paulo SP, Brasil; Email: ftmarivoos@gmail.com

Conflict of interest: There is no conflict of interest to declare.

Received 18 October 2016; Received in final form 15 May 2017; Accepted 16 May 2017. 
the progression of functional activities (description and scoring of compensatory movements). The FES-DMD has four domains: sitting and rising from a chair ${ }^{7}$; walking; ${ }^{8}$ climbing up and down steps ${ }^{9}$; and sitting down on, and standing up from the floor ${ }^{10}$. Excellent intra- and interrater reliabilities of all domains have been demonstrated ${ }^{7,8,9,10}$. In the FES-DMD, the tasks are videoed, which reduces evaluation time and patient fatigue (caused by the repetition of the activities). The scoring is based on the systematic observation of the videos and can also be performed with the assistance of FES-DMD-DATA software ${ }^{7}$. The FES-DMD-DATA offers the simultaneous observation of the video and the assessment chart on the same screen, which facilitates data collection and organization ${ }^{11}$.

Sitting down on, and standing up from the ground is a classic test to evaluate patients with DMD. However, many DMD patients stop performing this activity much earlier than their loss of gait. Therefore, sitting and standing from a chair can be a more accurate biomarker in the analysis of DMD progression prior to gait loss ${ }^{6}$. Sitting and rising from the chair is scored from 0-44 and 0-54, respectively. Sitting involves three phases: 1) trunk flexion, 2) hip contact with the chair and 3) trunk extension. Rising from the chair involves 1) trunk flexion, 2) weight transfer and 3) trunk extension. For both activities, higher scores denote a higher number of compensatory movements, therefore, poorer clinical and functional status?

Sit-to-stand was considered an accurate outcome measure to detect weight-bearing asymmetry ${ }^{12}$ and functional independence ${ }^{13}$ in stroke patients. However, in DMD patients, sit-to-stand and stand-to-sit have been poorly explored. Buckon et al. ${ }^{14}$ examined outcome responsiveness to corticosteroid therapy in ambulatory boys with DMD with timed tasks (10 meter running, sit-to-stand, supine-to-stand, climbing four steps). They found that only the timed performance of climbing four steps demonstrated a significant treatment effect. Boys on corticosteroid therapy climbed steps faster than those who were naive.

As sit-to-stand and stand-to-sit are performed within a few seconds, the analysis of compensatory movements provides more consistent biomarkers than a timed performance. Scrivener et al. ${ }^{15}$ described the responsiveness of sitto-stand in patients with stroke. They compared admission and discharge sit-to-stand performances and concluded that this test was highly responsive (able to detect clinical changes over time). However, the study had different follow-up periods, as the admission-discharge interval varied between the patients.

Reassessment time intervals must be determined to prevent examiners and clinicians from performing too many or too few reevaluations. The responsiveness analysis shows the proper reassessment intervals of a scale to detect significant clinical differences. This information is important in experimental designs and as well as to describe the natural progression ${ }^{2}$. In studies with patients with neuromuscular diseases, global motor measures, such as the Motor Function Measure ${ }^{2,16,17}$, North Star Ambulatory Assessment $^{18}$, Functional Independence Measure ${ }^{19}$, Barthel Index ${ }^{19}$ and Rehabilitation Activities Profile ${ }^{19}$ showed variable responsiveness in reassessment intervals ranging from six to 27 months.

Assessment instruments should be reliable, valid and responsive. Each test has specific reevaluation frequency recommendations, to prevent the collection of redundant information, or missing relevant data. No previous study has investigated the responsiveness of sit-to-stand and standto-sit tests in patients with neuromuscular disorders. In this study, we focus on the responsiveness of sitting and standing from the chair in DMD patients. As the lack of time and professionals available to perform long assessment protocols is common in clinical practice, sit-to-stand and stand-to-sit outcome measures can be useful when extensive protocols are not viable. The aim of this study was to investigate the responsiveness of sitting and standing from a chair in DMD patients in one year of follow up.

\section{METHODS}

This was an observational and longitudinal study, with one year of follow up, approved by the Ethics Committee of Clinics Hospital of Faculty of Medicine of University of São Paulo (process number 435/13).

\section{Participants}

Twenty-six ambulatory children (5-12 years old, $40.8 \pm 10.4 \mathrm{~kg} ; 1.39 \pm 0.17 \mathrm{~m}$; diagnosed with DMD by DNA analysis) performed sit-to-stand and stand-to-sit tasks. On the Brooke upper extremity scale, 15 boys were classified as 1 (they could abduct both arms in a full circle and touch above their head) and 11 were classified as 2 (they could raise their arms above their head by flexing the elbows or using accessory muscles). On the Vignos lower extremity scale, 10 boys were classified as 1 (they could walk and climb stairs without assistance), 10 were classified as 2 (they could climb stairs without the support of a railing) and six were classified as 3 (they took longer than 25 seconds to climb eight steps).

Each child was evaluated five times, in three-month intervals. Therefore, 130 videos of sit-to-stand and standto-sit were analyzed. All patients were prescribed corticosteroids and rehabilitation, according to the international consensus $^{1}$. All patients were receiving steroids at least six months prior to the first assessment.

\section{Procedures}

Videos were recorded in sagittal and frontal planes. Sit-to-stand and stand-to-sit tasks were performed using a standard chair (40 cm height, $40 \mathrm{~cm}$ length and $40 \mathrm{~cm}$ width) 
with a backrest and without arm support. The floor was covered with an anti-slip mat to prevent falls. The digital video camera was placed on a tripod, one meter high and two meters away from the chair. The evaluation and video analysis was conducted by a trained physiotherapist ${ }^{11}$, using FES-DMDDATA software.

Patients were recorded individually, every three months for a year. Responsiveness was calculated at three-, six-, nineand 12-month intervals. Therefore, we analyzed four periods of three months (0-3, 3-6, 6-9 and 9-12 months), three periods of six months (0-6, 3-9 and 6-12 months), two periods of nine months (0-9 and 3-12 months) and one period of 12 months (0-12 months). The first assessment was called assessment 0 (A0). The assessment after three months was named assessment 3 (A3) and the assessments after six, nine and 12 months were called assessments 6, 9 and 12 (A6, A9 and A12).

\section{Statistical analysis}

The effect sizes and the standardized response means were calculated. Effect sizes (ES) were calculated by dividing the mean change score by the standard deviation of the baseline score $^{20}$. The standardized response mean (SRM) was calculated by dividing the mean change score by the standard deviation of the score differences ${ }^{21}$. According to the Cohen criteria, values $\geq 0.20$ and $<0.50$ indicate low responsiveness, values $\geq 0.50$ and $<0.80$ indicate moderate responsiveness and values $\geq 0.8$ reflect high responsiveness for both measures ${ }^{22}$.

Table 1. Means and standard deviations (SD) of sit-to-stand and stand-to-sit in the initial assessment $(\mathrm{AO})$ and after three (A3), six (A6), nine (A9) and 12 months (A12).

\begin{tabular}{lccccc} 
Sit-to-stand & A0 & A3 & A6 & A9 & A12 \\
\hline Mean & 24.80 & 27.60 & 30.80 & 33.20 & 36.60 \\
SD & 9.30 & 10.80 & 10.80 & 10.90 & 11.40 \\
Stand-to-sit & A0 & A3 & A6 & A9 & A12 \\
Mean & 19.40 & 21.30 & 24.00 & 25.50 & 26.70 \\
SD & 6.50 & 5.40 & 5.90 & 4.60 & 4.80 \\
\hline
\end{tabular}

*A0: assessment 0, A3: assessment 3, A6: assessment 6, A9: assessment 9, A12: assessment 12.
After testing data for normality and homogeneity of variances, repeated measures analysis of variance (ANOVA) investigated differences between the sit-to-stand and standto-sit assessments. We considered as significant differences the values (p) lower than 0.05 .

\section{RESULTS}

Compensatory movements were employed by all children in performing sit-to-stand and stand-to-sit. The most common compensatory movements were knee hyperextension, internal rotation of the hips, trunk rotation and tilting and head tilting, rotation and hyperextension. Table 1 shows all means and standard deviations of the sit-to-stand and stand-to-sit scores.

Sit-to-stand showed low-to-moderate responsiveness in three-month intervals (ES: 0.23-0.32; SRM: 0.36-0.68), moderate-to-high responsiveness in six-month intervals (ES: 0.52-0.65; SRM: 0.76-1.28), and high in nine-(ES: 0.84-0.91; SRM:1.26-1.64)and twelve-monthintervals(ES:1.27;SRM:1.48). Stand-to-sit showed low responsiveness in three-month intervals (ES: 0.26-0.49; SRM: 0.37-0.42), moderate responsiveness in six-month intervals (ES: 0.50-0.78; SRM: 0.56-0.71), and high responsiveness in nine- (ES: 0.94-1.00; SRM: 0.84-1.02) and twelve-month intervals (ES: 1.13; SRM: 1.52). Table 2 shows the responsiveness analysis.

The ANOVA showed an interaction between tasks (sit-to-stand and stand-to-sit) and assessments (A0-A12), with $\mathrm{F}_{4,100}=2.762 ; \mathrm{p}=0.031$. Post hoc Tukey tests showed that in sit-to-stand, an A12 mean score was significantly higher than A0 (p<0.001), A3 (p<0.001), A6 (p<0.001) and A9 mean scores $(p=0.043)$. An A9 mean score was significantly higher than A0 and A3 mean scores $(p<0.001$ for both comparisons). An A6 mean score was significantly higher than A0 mean score $(p<0.001)$. Post hoc Tukey tests showed that in stand-to-sit, an A12 mean score was significantly higher than A0 and A3 mean scores ( $p<0.001$ for both comparisons). An A9 mean score was significantly higher than A0 ( $<<0.001)$ and A3 mean scores $(p=0.003)$. An A6 mean score was significantly higher than A0 mean score $(p=0.001)$ (Figure).

Table 2. Effect sizes (ES) and standardized response means (SRM) of sit-to-stand and stand-to-sit in three-, six-, nine- and 12 -month reassessment intervals.

\begin{tabular}{lccccccccccc}
\hline Sit-to-stand & $0 \times 3$ & $0 \times 6$ & $0 \times 9$ & $0 \times 12$ & $3 \times 6$ & $6 \times 9$ & $3 \times 9$ & $3 \times 12$ & $6 \times 12$ & $9 \times 12$ \\
\hline ES & 0.30 & 0.65 & 0.91 & 1.28 & 0.30 & 0.23 & 0.52 & 0.89 & 0.62 & 0.35 \\
SRM & 0.44 & 0.76 & 1.26 & 1.48 & 0.68 & 0.36 & 0.78 & 1.34 & 0.76 & 0.68 \\
Stand-to-sit & $0 \times 3$ & $0 \times 6$ & $0 \times 9$ & $0 \times 12$ & $3 \times 6$ & $6 \times 9$ & $3 \times 9$ & $3 \times 12$ & $6 \times 12$ & $9 \times 12$ \\
ES & 0.30 & 0.71 & 0.94 & 1.13 & 0.50 & 0.26 & 0.78 & 1.00 & 0.50 & 0.38 \\
SRM & 0.38 & 0.56 & 0.84 & 1.52 & 0.42 & 0.37 & 0.70 & 1.02 & 0.71 & 0.38
\end{tabular}

*Periods in months. Three-month intervals included assessments on all the following periods: 0-3, 3-6, 6-9 and 9-12 months. Six-month intervals included assessments on 0-6, 3-9 and 6-12 months. Nine-month intervals included periods: 0-9 and 3-12 months. The 12-month interval included the period 0-12 months. Higher effect sizes (ES) and standardized response means (SRM) denote higher responsiveness. 


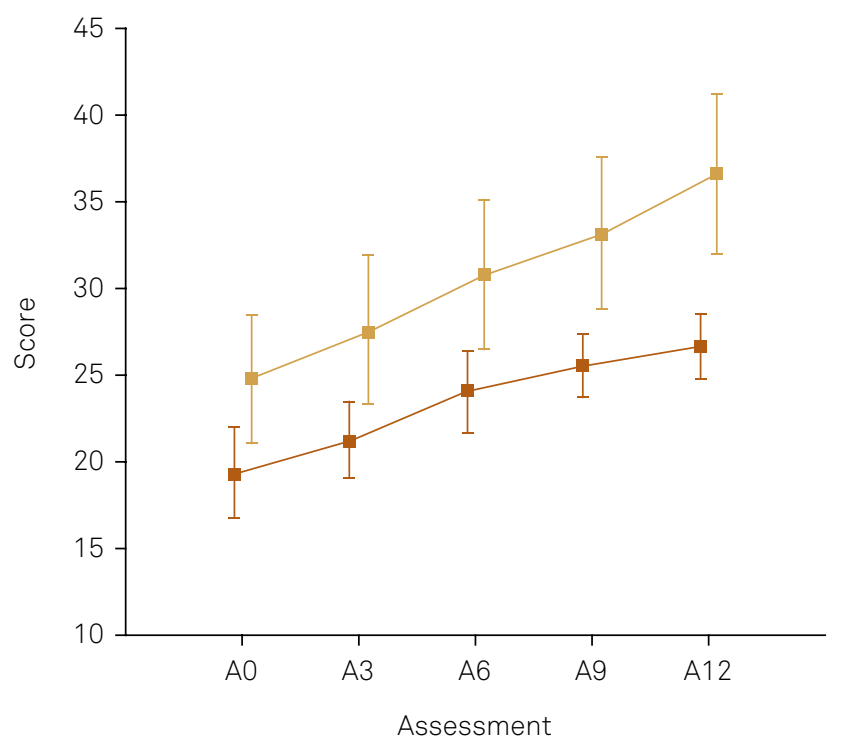

A0: assessment 0, A3: assessment 3, A6: assessment 6, A9: assessment 9, A12: assessment 12

Figure. Sit-to-stand and stand-to-sit scores on the Functional Evaluation Scale for Duchenne Muscular Dystrophy (domain sitting and rising from the chair) at the one year follow-up.

\section{DISCUSSION}

The present study hypothesized that distinct reassessment time intervals would show distinct responsiveness in sitting and standing from a chair in patients with DMD. Therefore, we investigated the responsiveness of sitting and standing from a chair in DMD patients over a one year follow-up. Our findings showed that sitting and standing from a chair should be evaluated in six-month or longer intervals, when moderate to high classifications were given for responsiveness measures (ES and SRM).

The identification of biomarkers, as outcome measures in patients with neuromuscular diseases, is extremely important for clinical and research purposes. The description of the natural progression of functional measures in DMD provide the baseline for studies with therapeutic interventions. The sitting and standing from a chair assessment has clinical relevance, as this activity is quick, simple and can be used to detect changes in motor behavior over time.

Previous studies have shown that patients need upper limb support and employ compensatory movements as DMD progresses ${ }^{23,24}$. The spontaneous selection of compensatory movements can vary among DMD patients, although some synergies are more frequent than others ${ }^{6}$. The progression of DMD is variable, due to genetic and environmental heterogeneity $^{23}$. Therefore, patients should be continuously monitored. Ambulatory DMD patients treated with steroids, aged 3-6 years, were evaluated with the North Star Ambulatory Assessment Scale. TheESranged from 0.39(low responsiveness) to 0.90 (high responsiveness) in 12-month intervals ${ }^{18}$. However, as only patients aged 3-6 years were included, the comparison with the present study is difficult.

The loss of eccentric muscle contraction affects sit-to-stand and, mainly, stand-to-sit. The child can let himself fall on the chair during the trunk flexion phase. A previous study showed that the absence of trunk flexion (contact phase) and trunk extension (extension phase) was due to impaired eccentric muscle contraction ${ }^{7}$. As well, patients performed compensatory movements, such as upper limb support and trunk rotation and lateral tilting ${ }^{7}$. In sit-to-stand, a progressive increase of the base of support with trunk flexion and rotation and upper limb support on the seat were observed. The transfer phase (when the hips were raised from the seat) was performed with bilateral ankle plantar flexion. Lower limb and trunk extensions were performed with upper limb support in the trunk extension phase?

Few studies have included responsiveness analysis, the recommendations of which must be clarified. Stucki et al. ${ }^{25}$ reported on a variety of tests and argued that no test was superior than another. Mehrholz et al. ${ }^{26}$ stated that the SRM could reflect individual changes better than the ES. However, Samsa et al. ${ }^{27}$ described the ES as effective and well accepted. Cano et al. ${ }^{28}$ recommended that the ES should be interpreted with caution and combined with other statistical methods to avoid misinterpretation ${ }^{28}$. Only six studies investigated the responsiveness of one or more tests for neuromuscular diseases ${ }^{2,16,17,18,19,29}$. Most studies used the ES ${ }^{18}$ and SRM ${ }^{2,16,17}$ in isolation or in combination ${ }^{19,29}$.

The Motor Function Measure showed good responsiveness in spinal muscular atrophy patients at six-month reassessment intervals. Responsiveness was higher in the months preceding ambulation loss ${ }^{16}$. The authors mentioned that fatigue interfered in testing. Therefore, specific focused tasks may be a less tiring alternative, preventing overload in clinical assessment. Another study used the Motor Function Measure to evaluate patients with CharcotMarie-Tooth type II and described moderate-to-high responsiveness. The SRM of dimensions one (standing and transferring) and three (distal motor function) were considered moderate (SRM $=0.68$ and 0.50 , respectively) and the total score of the SRM was high (SRM $=0.85)$. Mean reassessment intervals were much longer than in the present study $(27 \pm 17 \text { months })^{17}$.

The Motor Function Measure should not be used in intervals shorter than one year to evaluate patients with $\mathrm{DMD}^{2}$. The Motor Function Measure SRM has previously shown responsiveness at a one-year interval in patients with DMD (total score: 0.91; standing and transferring: 0.47; axial and proximal motor function: 0.68 ; distal motor function: 0.30$)^{2}$. The present study showed that sit-to-stand and stand-to-sit are more responsive outcome measures.

Our results showed that it was possible to observe some changes in sit-to-stand and stand-to-sit in three-month intervals. This information may be useful to monitor DMD 
progression and for clinical decision-making in some critical phases, e.g. when the patient is in transition from ambulation to wheelchair dependence. However, clinical changes will be more evident (classified as moderate and high) in longer reassessment intervals (six-month, or longer, intervals). Similar results were obtained by De Groot et al. ${ }^{19}$, who compared the responsiveness of the Functional Independence Measure, Barthel Index and Rehabilitation Activities Profile in patients with amyotrophic lateral sclerosis. All scales showed moderate responsiveness in six-month intervals and high responsiveness in 12-month intervals, considering ES and SRM measures. However, these scales depend on reports given by patients and provide less specific information about motor function.

As limitations of this study, we must mention that the analysis did not consider separate age groups and Brooke and Vignos scores, due to the sample size. Among younger patients, responsiveness tends to be lower, because compensatory movements are not required to preserve motor function. As DMD progresses, the number of compensatory movements increases, as sit-to-stand and stand-to-sit responsiveness. The conduction of the study in a single center, focusing on a population from Brazil's southeast, with similar cultural and socioeconomic characteristics may also limit generalizing our findings to other populations.

The present study shows that the sit-to-stand and stand-to-sit assessment provides useful outcome measures to detect DMD progression. Future studies should test these outcome measures in protocols with other types of neuromuscular diseases. The relationship between timed performance and FES-DMD domains with other clinical scales, such as the Motor Function Measure and the NorthStar Ambulatory Assessment Scale should be investigated.

In conclusion, sitting and standing from a chair can be assessed in six-month, or longer, intervals to evaluate DMD progression.

\section{References}

1. Bushby K, Finkel R, Birnkrant DJ, Case LE, Clemens PR, Cripe L, et al. Diagnosis and management of Duchenne muscular dystrophy, part 1: diagnosis, and pharmacological and psychosocial management. Lancet Neurol. 2010;9(1):77-93. https://doi.org/10.1016/S1474-4422(09)70271-6

2. Vuillerot C, Payan C, Girardot F, Fermanian J, Iwaz J, Bérard C et al. Responsiveness of the motor function measure in neuromuscular diseases. Arch Phys Med Rehabil. 2012;93(12):2251-6.e1. https://doi.org/10.1016/j.apmr.2012.05.025

3. Brooke MH, Griggs RC, Mendell JR, Fenichel GM, Shumate JB, Pellegrino RJ. Clinical trial in Duchenne dystrophy. I. The design of the protocol. Muscle Nerve. 1981;4(3):186-97. https://doi.org/10.1002/mus.880040304

4. Vignos PJ, Spencer GE, Archibald KC. Management of progressive muscular dystrophy in childhood. JAMA. 1963;184(2):89-96. https://doi.org/10.1001/jama.1963.03700150043007

5. Vuillerot C, Girardot F, Payan C, Fermanian J, Iwaz J, De Lattre $\mathrm{C}$ et al. Monitoring changes and predicting loss of ambulation in Duchenne muscular dystrophy with Motor Function Measure. Dev Med Child Neurol. 2010;52(1):60-5. https://doi.org/10.1111/j.1469-8749.2009.03316.x

6. Martini J, Voos MC, Hukuda ME, Resende MB, Caromano FA. Compensatory movements during functional activities in ambulatory children with Duchenne muscular dystrophy. Arq Neuropsiquiatr. 2014;72(1):5-11. https://doi.org/10.1590/0004-282X20130196

7. Hukuda ME, Escorcio R, Fernandes LA, Carvalho EV, Caromano FA. Evaluation scale development, reliability for sitting and standing from the chair for Duchenne muscular dystrophy. J Mot Behav. 2013;45(2):117-26. https://doi.org/10.1080/00222895.2012.760513

8. Carvalho EV, Hukuda ME, Escorcio R, Voos MC, Caromano FA. Development and reliability of the functional evaluation scale for Duchenne muscular dystrophy, Gait domain: a pilot study. Physiother Res Int. 2015;20(3):135-46. https://doi.org/10.1002/pri.1605

9. Fernandes LAY, Caromano FA, Hukuda ME, Escorcio R, Carvalho EV. Elaboration and reliability of functional evaluation on going up and downstairs scale for Duchenne Muscular Dystrophy. Rev Bras Fisioter. 2010;14(6):518-26. https://doi.org/10.1590/S1413-35552010000600011
10. Escorcio R, Caromano FA, Hukuda ME, Fernandes LAY. Development of an evaluation scale for sitting and standing from the ground for children with Duchenne muscular dystrophy. J Mot Behav. 2011;43(1):31-6. https://doi.org/10.1080/00222895.2010.530306

11. Albuquerque PS. Development of software for application of functional scale of people with Duchenne muscular dystrophy and usability testing [thesis]. São Paulo: Universidade de São Paulo; 2013.

12. Nadeau SM, Boukadida A, Piotte F, Mesure S. Weight-bearing perception during standing and sit-to-stand tasks in subacute post-stroke individuals undergoing intensive rehabilitation. Ann Phys Rehabil Med. 2016;59 Suppl:e71-2. https://doi.org/10.1016/j.rehab.2016.07.166

13. Lee G, An S, Lee Y, Park DS. Clinical measures as valid predictors and discriminators of the level of community ambulation of hemiparetic stroke survivors. J Phys Ther Sci. 2016;28(8):2184-9. https://doi.org/10.1589/jpts.28.2184

14. Buckon C, Sienko S, Bagley A, Sison-Williamson M, Fowler E, Staudt L et al. Can quantitative muscle strength and functional motor ability differentiate the influence of age and corticosteroids in ambulatory boys with Duchenne muscular dystrophy?. PLoS Curr. 2016 Jul 8. Edition 1. https://doi.org/10.1371/currents.md.1 ced64dff945f8958221fddcd4ee60b0.

15. Scrivener K, Schurr K, Sherrington C. Responsiveness of the ten-metre walk test, Step Test and Motor Assessment Scale in inpatient care after stroke. BMC Neurol. 2014;14(1):129. https://doi.org/10.1186/1471-2377-14-129

16. Vuillerot C, Payan C, Iwaz J, Ecochard R, Bérard C. Responsiveness of the Motor Function Measure in patients with spinal muscular atrophy. Arch Phys Med Rehabil. 2013;94(8):1555-61. https://doi.org/10.1016/j.apmr.2013.01.014

17. Allard L, Rode G, Jacquin-Courtois S, Pouget MC, Rippert P, Hamroun D et al. The motor function measure to study limitation of activity in children and adults with Charcot-Marie-Tooth disease. Ann Phys Rehabil Med. 2014;57(9-10):587-99. https://doi.org/10.1016/j.rehab.2014.09.005

18. Mayhew AG, Cano SJ, Scott E, Eagle M, Bushby K, Manzur A et al. Detecting meaningful change using the North Star Ambulatory Assessment in Duchenne muscular dystrophy. Dev Med Child Neurol. 2013;55(11):1046-52. https://doi.org/10.1111/dmcn.12220 
19. De Groot IJ, Post MW, Van Heuveln T, Van Den Berg LH, Lindeman E. Measurement of decline of functioning in persons with amyotrophic lateral sclerosis: responsiveness and possible applications of the Functional Independence Measure, Barthel Index, Rehabilitation Activities Profile and Frenchay Activities Index. Amyotroph Lateral Scler. 2006;7(3):167-72. https://doi.org/10.1080/14660820600640620

20. Kazis LE, Anderson JJ, Meenan RF. Effect sizes for interpreting changes in health status. Med Care. 1989;27(3 Suppl):178-89. https://doi.org/10.1097/00005650-198903001-00015

21. Liang $M H$, Fossel $A H$, Larson MG. Comparisons of five health status instruments for orthopedic evaluation. Med Care. 1990;2(7)8:632-42. https://doi.org/10.1097/00005650-199007000-00008

22. Cohen J. Statistical power analysis for the behavioral sciences. 2nd ed. Hillsdale: Lawrence Earlbaum; 1988.

23. Brooke MH, Fenichel GM, Griggs RC, Mendell JR, Moxley R, Florence $\mathrm{J}$ et al. Duchenne muscular dystrophy: patterns of clinical progression and effects of supportive therapy. Neurology. 1989;39(4):475-81. https://doi.org/10.1212/WNL.39.4.475

24. Mayhew A, Mazzone ES, Eagle M, Duong T, Ash M, Decostre V et al. Development of the Performance of the Upper Limb module for Duchenne muscular dystrophy. Dev Med Child Neurol. 2013;55(11):1038-45. https://doi.org/10.1111/dmcn.12213
25. Stucki G, Liang MH, Fossel AH, Katz JN. Relative responsiveness of condition-specific and generic health status measures in degenerative lumbar spinal stenosis. J Clin Epidemiol. 1995;48(11):1369-78. https://doi.org/10.1016/0895-4356(95)00054-2

26. Mehrholz J, Wagner K, Rutte K, Meissner D, Pohl M. Predictive validity and responsiveness of the functional ambulation category in hemiparetic patients after stroke. Arch Phys Med Rehabil. 2007;88(10):1314-9. https://doi.org/10.1016/j.apmr.2007.06.764

27. Samsa G, Edelman D, Rothman ML, Williams GR, Lipscomb J, Matchar D. Determining clinically important differences in health status measures: a general approach with illustration to the Health Utilities Index Mark II. Pharmacoeconomics. 1999;15(2):141-55. https://doi.org/10.2165/00019053-199915020-00003

28. Cano SJ, O'Connor RJ, Thompson AJ, Hobart JC. Exploring disability rating scale responsiveness II: do more response options help?. Neurology. 2006;67(11):2056-9. https://doi.org/10.1212/01.wnl.0000247664.97643.e8

29. Vandervelde L, Van den Bergh PY, Goemans N, Thonnard JL. Activity limitations in patients with neuromuscular disorders: a responsiveness study of the ACTIVLIM questionnaire. Neuromuscul Disord. 2009;19(2):99-103. https://doi.org/10.1016/j.nmd.2008.11.004 